https://helda.helsinki.fi

\title{
Vitality, Language Use, and Life Satisfaction : A Study of Bilingual Hungarian Adolescents Living in Romania
}

\section{Dragojevic, Marko}

2018-09

Dragojevic , M , Gasiorek , J \& Vincze , L 2018 , ' Vitality, Language Use, and Life Satisfaction : A Study of Bilingual Hungarian Adolescents Living in Romania ' , Journal of Language and Social Psychology, vol. 37 , no. 4 , pp. 431-450 . https://doi.org/10.1177/0261927X17729437

http://hdl.handle.net/10138/327459

https://doi.org/10.1177/0261927X17729437

unspecified

acceptedVersion

Downloaded from Helda, University of Helsinki institutional repository.

This is an electronic reprint of the original article.

This reprint may differ from the original in pagination and typographic detail.

Please cite the original version. 
Vitality, Language Use, and Life Satisfaction:

\title{
A Study of Bilingual Hungarian Adolescents Living in Romania
}

Marko Dragojevic ${ }^{1}$, Jessica Gasiorek ${ }^{2}$, László Vincze ${ }^{3}$

\begin{abstract}
This study examined the relationship between objective and subjective vitality, ingroup language use, and life satisfaction among two groups of bilingual Hungarians adolescents living in Romania: a low objective vitality (LOV) group from Cluj-Napoca/Kolozsvár, where Hungarians are the demographic minority, and a high objective vitality (HOV) group from Sfântu Gheorghe/Sepsiszentgyörgy, where Hungarians are the demographic majority. Consistent with predictions, the HOV group reported higher subjective Hungarian vitality, lower subjective Romanian vitality, more frequent use of the Hungarian language, and higher life satisfaction, compared to the LOV group. The effects of objective vitality on language use were partially mediated by subjective Romanian (but not Hungarian) vitality. Conversely, the effects of objective vitality on life satisfaction were fully mediated by subjective Hungarian (but not Romanian) vitality.
\end{abstract}

\section{Keywords:}

ethnolinguistic vitality, intergroup, language use, life satisfaction

${ }^{1}$ Department of Communication, University of Kentucky, Lexington, KY, USA

${ }^{2}$ Department of Communicology, University of Hawaii at Manoa, Honolulu, HI, USA

${ }^{3}$ Swedish School of Social Science, University of Helsinki, Helsinki, Finland

\section{Corresponding Author}


Marko Dragojevic, Department of Communication, University of Kentucky, 242 Grehan Bldg., Lexington, KY 40506, marko.dragojevic@uky.edu

\section{Citation}

Dragojevic, M., Gasiorek, J., \& Vincze, L. (2018). Vitality, language use, and life satisfaction: A study of bilingual Hungarian adolescents living in Romania. Journal of Language and Social Psychology, 37(4), 431-450. https://doi.org/10.1177/0261927X17729437 
Ethnolinguistic vitality, defined as "that which makes a group likely to behave as a distinctive and active collective entity in intergroup situations" (Giles, Taylor, \& Bourhis, 1977, p. 308), has received considerable attention as a useful conceptual tool for discussing and predicting a range of language-related phenomena, including language use (e.g., Allard \& Landry, 1994; Bourhis, 1984; Sachdev, Bourhis, Phang, \& D’Eye, 1987; Stell \& Dragojevic, 2017), language attitudes (e.g, Bourhis \& Sachdev, 1984; Dragojevic, 2016; Kraemer, Olshtain, \& Badier, 1994; Lawson \& Sachdev, 2004), linguistic landscapes (e.g., Landry \& Bourhis, 1997) and language learning (e.g., Giles \& Byrne, 1982; Marton, Joyce, \& Vincze, 2014), among others (for the most recent review, see Smith, Ehala, \& Giles, in press). However, less attention has been devoted to understanding how ethnolinguistic vitality and its linguistic correlates influence non-linguistic outcomes, such as group members' life satisfaction (but see Crozier, 1999; Currie \& Hogg, 1994). This is surprising, given that ethnolinguistic vitality has direct bearing on the outcome of intergroup comparisons (Giles et al., 1977; Giles \& Johnson, 1981, 1987), which can influence group members' psychological well-being (Haslam, Jetten, Postmes, \& Haslam, 2009; Tajfel \& Turner, 1986).

In an attempt to address this gap in the literature, the present study examined the relationship between ethnolinguistic vitality, language use, and life satisfaction among bilingual Hungarian adolescents living in Romania. In the sections that follow, we first provide a brief overview of the vitality construct and discuss its relationship to language use and psychological well-being. Next, we contextualize the present research and advance a theoretical model explicating the relationships between our variables of interest. Then, we describe the present study and report our findings.

\section{Ethnolinguistic Vitality, Language Use, and Life Satisfaction}


Ethnolinguistic vitality reflects a group's strength and cohesiveness in a given social context (Giles et al., 1977; Harwood, Giles, \& Bourhis, 1994; Smith et al., in press). Three sociostructural factors are proposed to influence the vitality of ethnolinguistic groups: demographics, status, and institutional support. Demographics refer to a group's size (e.g., absolute number, rates of birth and death) and distribution (e.g., concentration, relative proportion of group members) in a given social context. The stronger a group is demographically, the more vitality it has. Status refers to the economic, social, and sociohistorical power and prestige of a group (and its language) in a given context. High status groups have more vitality than low status groups. Finally, institutional support refers to a group's visibility in and recognition (both formal and informal) by various social institutions, including the government, schools, and media. The more support a group (and its language) has from relevant social institutions, the more vitality it has. Any given group's position on these three factors can be combined to classify the group as having overall low, medium, or high vitality. Groups that have high vitality are more likely to survive as distinctive collective entities than groups that have low vitality (Giles et al., 1977).

Vitality can be assessed both objectively and subjectively. Objective vitality reflects a group's actual (i.e., objectively measurable and quantifiable) position on the three sociostructural variables discussed above (Giles et al., 1977; Harwood et al., 1994). Subjective vitality, in contrast, reflects people's perceptions of a group's overall strength and cohesiveness (Abrams, Barker, \& Giles, 2009; Bourhis, Giles, \& Rosenthal, 1981). Frequently, subjective and objective vitality coincide and people's perceptions of a group's vitality reflect the group's actual (objectively measurable) vitality (e.g., Giles \& Johnson, 1987; Landry, Allard, \& Deveau, 2010; Lawson \& Sachdev, 2004; Sachdev et al., 1987; Ytsma, Viladot, \& Giles, 1994). Such 'realistic' 
vitality assessments tend to emerge in stable intergroup contexts, marked by an absence of significant sociopolitical and economic instability and conflict (Harwood et al., 1994). Other times, however, subjective assessments of a group's vitality may be biased in terms of degree and/or direction (e.g., Bourhis \& Sachdev, 1984; Yagmur \& Akinci, 2003). Such 'perceptual distortions' are more likely to emerge in unstable intergroup contexts, marked by significant sociopolitical and economic instability and conflict (Harwood et al., 1994). In line with the notion that intergroup behavior is mediated by members' cognitive representations of the intergroup context, it has been proposed that subjective vitality mediates the effect of objective vitality on intergroup behavior, including language use (Bourhis et al., 1981; Harwood et al., 1994; Johnson, Giles, \& Bourhis, 1983; Smith et al., in press).

Ethnolinguistic vitality has been a useful conceptual tool in explaining and predicting a range of language-related phenomena, particularly language choice and maintenance among multilingual individuals (for a discussion, see Harwood et al., 1994; Smith et al., in press). Objective and subjective vitality have both emerged as useful constructs in this endeavor. In general, research has shown that groups that have high objective vitality are more likely to maintain and use their ingroup language in different contexts than groups that have relatively low objective vitality (e.g., Bourhis, 1984; Bourhis \& Sachdev, 1984; Landry \& Allard, 1994; Landry et al., 2010; Stell \& Dragojevic, 2016). Similarly, past studies have shown that subjective ingroup vitality is positively related to ingroup language use (e.g., Allard \& Landry, 1994; Yagmur \& Akinci, 2003), whereas subjective outgroup vitality is negatively related to ingroup language use (e.g., Lawson \& Sachdev, 2004). That is, the more vitality people perceive their ingroup to possess in comparison to a relevant outgroup, the more likely they are to use the ingroup language. Conversely, the more vitality people perceive a relevant outgroup to possess 
in comparison to the ingroup, the less likely they are to use the ingroup language. Interestingly, however, and despite the theoretical claim that subjective vitality mediates the effect of objective vitality on language use (Bourhis et al., 1981; Johnson et al., 1983; Harwood et al., 1994), we are aware of no research that has empirically demonstrated this relationship (but see Vincze \& Harwood, 2014); this is one goal of the present study.

Vitality has also been a useful conceptual tool in predicting and explaining various nonlinguistic phenomena, such as media selection and use among ethnolinguistic minorities (Abrams \& Giles, 2009; Harwood \& Vincze, 2012, 2015; Reid, Giles, \& Abrams, 2004; Viladot, Giles, Gasiorek, \& Esteban-Guitart, 2012) and educational achievement (Currie \& Hogg, 1994). In addition to these, ethnolinguistic vitality may also have implications for group members' general life satisfaction. According to social identity theory (SIT: Tajfel \& Turner, 1986), people are motivated to maintain a positive self-concept because doing so promotes psychological wellbeing; extant research provides broad support for this assertion (see Leary, 2007; Sedikides, Gaertner, \& Vevea, 2005; Sedikides, Skowronski, \& Gaertner, 2004; but see also, Heine, 2005). The self-concept, according to SIT, consists of two components: personal identity (i.e., idiosyncratic characteristics that make one unique) and social identity (i.e., one's social group memberships). Because part of the self-concept derives from one's social group memberships, SIT posits that people are motivated to create and maintain positive social identities in an effort to enhance their psychological well-being. Indeed, a growing body of literature supports the assertion that a favorable social identity promotes psychological well-being - that is, feeling good about the groups they belong to helps people feel good about themselves (see Haslam et al., 2009; Rubin \& Hewstone, 1998). For instance, past research has shown that mere identification with a social group - even a stigmatized one - can enhance psychological well-being by 
providing group members with various psychological resources (e.g., increased sense of belonging, perceived social support, collective self-esteem: e.g., Branscombe \& Wann, 1991; Jetten et al., 2015). However, these general benefits of group identification tend to be attenuated for individuals who identify with stigmatized or negatively-viewed groups, because internalization of a negative social identity can also diminish psychological well-being (e.g., Cooper, Smith, \& Russell, in press; Crabtree, Haslam, Postmes, \& Haslam, 2010). In other words, while mere group membership appears to be good for psychological well-being, these effects may be enhanced for individuals who are able to derive a positive social identity from the groups they identify with.

Ethnolinguistic identity theory (ELIT: Giles \& Johnson, 1981; 1987) expands SIT by positing that language is a central aspect of social identity and, as a result, that people are motivated to create and maintain a positive ethnolinguistic identity as a way to enhance their psychological well-being. According to SIT and ELIT, one way in which people can achieve this is through favorable intergroup comparisons that render their ingroup positively distinct from relevant outgroups on evaluative dimensions of importance (Tajfel \& Turner, 1986). A group's ethnolinguistic vitality has direct bearing on the outcome of such comparisons because it is an indicator of the group's strength and position in society (Giles et al., 1977). Namely, the more vitality one's ingroup has in comparison to a relevant outgroup, the stronger the ingroup's relative social position and the more it lends itself to favorable intergroup comparisons and the establishment of positive distinctiveness. This should enhance ingroup members' psychological well-being and life satisfaction via internalization of a positive social identity. Conversely, and related, the more vitality a relevant outgroup has in comparison to the ingroup, the weaker the ingroup's relative social position and the less it lends itself to favorable intergroup comparisons, 
which should dampen ingroup members' psychological well-being and life satisfaction via internalization of a less positive social identity. Beyond influencing the outcome of intergroup comparisons, increased vitality (particularly when due to demographic strength) may also provide group members with an increased sense of security and a larger social support network, which, in turn, may enhance psychological well-being (e.g., Siedlecki, Salthouse, Oishi, \& Jeswani, 2014; for a discussion, see Diener, 2009; Haslam et al., 2009). Additionally, vitality may also influence life satisfaction indirectly, by influencing ingroup language use. Specifically, to the extent that ingroup language use is a valued enactment of ingroup identity (Giles et al., 1977), then increases in ingroup vitality may indirectly enhance psychological well-being by promoting ingroup language use. Conversely, increases in outgroup vitality may indirectly dampen psychological well-being by reducing ingroup language use. In sum, increases in objective and subjective ingroup vitality are likely to enhance ingroup members' life satisfaction, whereas increases in objective and subjective outgroup vitality are likely to reduce it.

Extant research provides some support for these assertions. For example, Currie and Hogg (1994) found a positive correlation between subjective ingroup vitality and life satisfaction among Vietnamese refugees living in Australia. Similarly, Crozier (1999) found that subjective ingroup vitality was positively associated with psychological well-being among various ethnolinguistic groups living in Montreal. Both of these studies, however, focused on subjective vitality and examined how intragroup variation in that construct is related to intragroup variation in life satisfaction. We are not aware of any research that has directly examined how intergroup differences in objective and subjective vitality may predict differences in life satisfaction across groups. 
Research on acculturation provides some tentative support for the assertion that ingroup language use promotes psychological well-being. Specifically, this research has shown that minority group members who pursue integration - i.e., who maintain their own cultural practices, including maintenance and use of their language, whilst simultaneously adopting the dominant group's cultural practices and language - tend to report better psychological outcomes than those who pursue assimilation - i.e., who abandon their own cultural practices, including their language, in favor of the dominant group's cultural practices and language (see Berry, 1997, 2005; Berry, Phiney, Sam, \& Vedder, 2006). However, in this line of research, language use is typically one of many potential variables that determine people's acculturative orientation (i.e., the extent to which they pursue integration, assimilation, or other strategies). Consequently, it is often difficult to determine the effects that language use, in isolation, has on psychological well-being (but see e.g., Chen, Benet-Martínez, \& Bond, 2008; Marsiglia, Booth, Baldwin, \& Ayers, 2013). Moreover, most acculturation research has focused on immigrant communities, rather than non-immigrant ethnolinguistic minorities, which are the focus of the present research (but see, Gaudet \& Clément, 2005; Noels \& Clément, 1996).

\section{The Present Study}

The present study examined the relationship between objective and subjective vitality, ingroup language use, and life satisfaction among bilingual Hungarian adolescents living in Romania. Romania is a country in Eastern Europe and part of the European Union. Hungarians are the largest ethnic minority in Romania, constituting approximately $6 \%$ of the country's population with about 1.2 million members. Most ethnic Hungarians live in Transylvania, a region located in the central part of the country, which used to be part of the Austro-Hungarian Empire. According to Romania's minority rights law, Hungarians have the right to education in their 
native language, including as the medium of instruction. In addition, in localities where Hungarians make up more than $20 \%$ of the population, they also have the right to use their native language with local authorities. In practice, however, the linguistic opportunities afforded by this law are often limited given that the majority of employees in the public section are Romanian speakers and generally do not speak Hungarian, even in localities where Hungarians are the majority of the local population (see Péntek \& Benő, 2003).

Based on the above, Hungarians can be classified as having, moderate overall objective vitality in Romania. However, and notwithstanding this generalization, the relative objective vitality of Hungarians varies considerably across different localities, due primarily to differences in demographic distribution. The present study focused on Hungarians living in two localities: Cluj-Napoca/Kolozsvár and Sfântu Gheorghe/Sepsiszentgyörgy. Both are cities in Transylvania, with 325,000 and 55,000 inhabitants, respectively. In Cluj-Napoca/Kolozsvár, Hungarians are the demographic minority (16\%) and Romanians the majority (82\%). Conversely, in Sfântu Gheorghe/Sepsiszentgyörgy, Hungarians are the demographic majority (77\%) and Romanians the minority (22\%). As a result of these demographic differences, Hungarians in Sfântu Gheorghe/Sepsiszentgyörgy also enjoy greater institutional support, because their local demographic majority status affords them additional linguistic rights under the minority rights laws outlined above. Based on this, Hungarians living in Cluj-Napoca/Kolozsvár can be classified as having relatively low objective vitality - hereafter referred to as the low objective vitality (LOV) group - whereas those living in Sfântu Gheorghe/Sepsiszentgyörgy can be classified as having relatively high objective vitality - hereafter referred to as the high objective vitality (HOV) group. 
We expected these differences in objective vitality between the two groups to result in differences in (a) subjective vitality, (b) use of the Hungarian language, and (c) life satisfaction. The proposed relationship among these variables is depicted in the theoretical model in Figure 1 and described below.

[Insert Figure 1 here]

First, we expected objective differences in vitality across the two groups to produce corresponding differences in subjective vitality (Figure 1, path $a$ ). As explained earlier, Hungarians have more objective vitality in Sfântu Gheorghe/Sepsiszentgyörgy, where they constitute the demographic majority, than in Cluj-Napoca/Kolozsvár, where they constitute the demographic minority. Conversely, and related, Romanians have less objective vitality in Sfântu Gheorghe/Sepsiszentgyörgy, where they constitute the demographic minority, than in ClujNapoca/Kolozsvár, where they constitute the demographic majority. We expected the LOV and HOV groups' perceptions of local Hungarian and Romanian vitality to mirror this objective reality (cf. Harwood et al., 1994). Specifically, when judging the vitality of Hungarians and Romanians in their respective locality, we expected the HOV group to perceive Hungarians to have more vitality and Romanians to have less vitality than the LOV group. Stated formally:

$\mathrm{H}_{1 \mathrm{a}-\mathrm{b}}$ : Compared to the LOV group, the HOV group will perceive (a) local Hungarian vitality to be higher and (b) local Romanian vitality to be lower.

Next, we expected these differences in subjective vitality across the two groups to produce differences in language use (Figure 1, path $b$ ). As noted earlier, increases in subjective ingroup vitality promote use of the ingroup language, whereas increases in subjective outgroup vitality constrain it (Harwood et al., 1994). Accordingly, given that the HOV group is likely to perceive Hungarian (i.e., ingroup) vitality to be higher and Romanian (i.e., outgroup) vitality to 
be lower in their respective locality than the LOV group $\left(\mathrm{H}_{1}\right)$ - both cognitions that should promote use of the Hungarian language - it then logically follows that the HOV group is likely to speak Hungarian more frequently than the LOV group. Accordingly, we predicted that:

$\mathrm{H}_{2}$ : Compared to the LOV group, the HOV group will report speaking more Hungarian (relative to Romanian).

Implicit in the above rationale is the notion that subjective vitality mediates the effect of objective vitality on language use (Figure 1, path $a^{*} b$ ). That is, the HOV group is expected to use more Hungarian than the LOV group because the former perceive Hungarians to have more vitality and Romanians to have less vitality in their respective locality. Accordingly, and consistent with the argument that intergroup behavior is cognitively mediated (Johnson et al., 1983; Harwood et al., 1994), we predicted that:

$\mathrm{H}_{3}$ : The effects of objectively vitality on Hungarian language use will be mediated by subjective (Hungarian and Romanian) vitality.

We also expected the two groups to differ in terms of life satisfaction. As argued earlier, increases in subjective ingroup vitality promote more favorable intergroup comparisons - which should enhance life satisfaction - whereas increases in subjective outgroup vitality hinder favorable intergroup comparisons - which should reduce life satisfaction (Figure 1, path $c$ ). In addition, to the extent that ingroup language use is a valued enactment of one's ingroup identity (Giles et al., 1977), then increased use of the ingroup language should also promote higher life satisfaction (Figure 1, path $d$ ). As outlined above, the HOV group is likely to (a) perceive Hungarian vitality to be higher and Romanian to be lower in their respective locality $\left(\mathrm{H}_{1}\right)$ and (b) speak Hungarian more frequently $\left(\mathrm{H}_{2}\right)$ than the LOV group. These should all be conducive to 
psychological well-being; thus, it then logically follows that the HOV group is also likely to report higher life satisfaction. Stated formally:

$\mathrm{H}_{4}$ : Compared to the LOV group, the HOV group will report higher life satisfaction. Implicit in the above rationale is the notion that the effects of objective vitality on life satisfaction are mediated by subjective (Hungarian and Romanian) vitality (Figure 1, path $a^{*} c$ ) and sequentially by subjective vitality and ingroup language use (Figure 1, path $a^{*} b^{*} d$ ). That is, the reason the HOV group is expected to report higher life satisfaction than the LOV group is because the former perceive Hungarian vitality to be higher and Romanian vitality to be lower in their respective locality and speak Hungarian more frequently. Accordingly, we predicted that:

$\mathrm{H}_{5 \mathrm{a}-\mathrm{b}}$ : The effects of objective vitality on life satisfaction will be mediated by (a) subjective (Hungarian and Romanian) vitality and (b) sequentially by subjective vitality and ingroup language use.

Above and beyond the indirect effects proposed above, we also were interested in whether objective vitality would have a direct effect on language use (Figure 1, path $e$ ) and life satisfaction (Figure 1, path f). Indeed, regardless of how group members perceive their group's vitality, it is likely that the objective reality of the intergroup context has bearing on these outcomes (e.g., greater opportunities to use the ingroup language: see Landry et al., 2010). Thus, we posed the following research questions:

$\mathrm{RQ}_{1}$ : Will objective vitality have a direct effect on language use?

$\mathrm{RQ}_{2}$ : Will objective vitality have a direct effect on life satisfaction?

\section{Method}

\section{Participants}


Completed questionnaires were obtained from 378 self-identified ethnic Hungarians living in Romania. One case was identified as a univariate outlier on the language use variable (z-score = 4.47) and was excluded from all analyses. Thus, the final sample consisted of 377 participants $(53.6 \%$ female $)$ who ranged in age from 14 to $18(M=16.12 ; S D=0.90)$. All participants were Hungarian-Romanian bilinguals. Participants were classified into one of two groups based on their locality of residence and its associated demographics. Participants from ClujNapoca/Kolozsvár $\left(n=186 ; 46.2 \%\right.$ female; $\left.M_{\text {age }}=15.94\right)$, where Hungarians are the demographic minority, were classified as the low objective vitality (LOV) group. Participants from Sfântu Gheorghe/Sepsiszentgyörgy $\left(n=191 ; 60.7 \%\right.$ female; $\left.M_{\text {age }}=16.29\right)$, where Hungarians are the demographic majority, were classified as the high objective vitality (HOV) group. Participants in the HOV group were slightly older, $t(375)=-3.94, p<.001$, and more likely to be female, $\chi^{2}(1)=7.96, p=.005$, than participants in the LOV group.

\section{Procedure}

The study was conducted at two secondary schools in Romania: one in Cluj-Napoca/Kolozsvár (the LOV group) and one in Sfântu Gheorghe/Sepsiszentgyörgy (the HOV group). At both schools, the language of instruction is Hungarian. A paper-and-pencil questionnaire was administered to all students who were present in class on the day of data collection. The questionnaire was administered in Hungarian (translated by the third author) and students completed it individually.

\section{Measures}

Subjective vitality. Subjective Hungarian and Romanian vitality were assessed by having participants indicate how active each ethnolinguistic group currently is in their respective locality (i.e., in Cluj-Napoca/Kolozsvár or Sfântu Gheorghe/Sepsiszentgyörgy) using a 7-point scale (1 = 
not at all; 7 = very). This item was adapted from past research (e.g., Bourhis \& Sachdev, 1984) and reflects Giles and colleagues' (1977) initial conceptualization of vitality as "that which makes a group likely to behave as a distinctive and active collective entity" (p. 308; emphasis added). Subjective Hungarian $(M=5.19 ; S D=1.19)$ and Romanian vitality $(M=4.62 ; S D=$ 1.39) were negatively correlated $(r=-.12, p<.02)$.

Language use. Hungarian and Romanian language use were assessed by having participants indicate the extent to which they used each language with family, with friends, in the city, and with public administration using 5-point scales $(0=$ never, $4=$ always $)$. These four items were averaged for each language to form an index of Hungarian language use $(\alpha=.70 ; M=2.91 ; S D$ $=0.64)$ and Romanian language use $(\alpha=.71 ; M=1.42 ; S D=0.68)$. Unsurprisingly, the two scales were strongly and negatively correlated $(r=-.73 ; p<.001)$. Consequently, we calculated an index of relative Hungarian use by dividing each participant's Hungarian language use by their total Romanian and Hungarian language use (for other procedures, see Allard \& Landry, 1994). This index reflects the proportion of time participants reported speaking Hungarian relative to their total Hungarian and Romanian language use and had a theoretical range of 0 (only Romanian spoken) to 1 (only Hungarian spoken) $(M=0.67 ; S D=0.15)$.

Life satisfaction. Life satisfaction was assessed using the Satisfaction with Life Scale (SWLS; Diener, Emmons, Larsen, \& Griffin, 1985), which asks participants to indicate their agreement or disagreement with five statements (e.g., In most ways my life is close to my ideal; I am satisfied with my life) using 5-point scales ( $1=$ strongly disagree; $5=$ strongly agree). These five items were averaged to form the life satisfaction scale $(\alpha=.73 ; M=3.41 ; S D=0.71)$.

Covariates. Given that participants from the HOV group tended to be slightly older and were more likely to be female than participants from the LOV group, as noted earlier, age and sex 
were treated as covariates in all analyses. Additionally, we assessed participants' subjective stress and health to serve as covariates in our analysis of life satisfaction, given the potential of these variables to influence psychological well-being. Subjective stress was assessed using the four-item version of the Perceived Stress Scale (PSS; Cohen, Kamarck, \& Mermelstein, 1983), which asks participants to respond to four items (e.g., In the last month, how often have you felt that you were unable to control the important things in life? $)$ using 5-point scales $(1=$ never; $5=$ very often). These four items were averaged to form the subjective stress scale $(\alpha=.76 ; M=$ 2.64; $S D=0.74)$. Subjective health was assessed by having participants respond to the first item of the Center for Disease Control (CDC) Healthy Days Measure, which asks participants to respond to the stem "Would you say that in general your health is" using "excellent," "very good," "good," "fair," or "poor." The item was coded such that higher values indicate better subjective health $($ range $=1-5 ; M=3.76 ; S D=0.84)$.

\section{Results}

\section{Preliminary Analyses}

An initial check for normality of distributions revealed that all variables were normally distributed (all $\left|Z_{\text {skewness }}\right|<3.29$; see Tabachnick \& Fidell, 2007).

\section{Focal Analyses}

$\mathrm{H}_{1 \mathrm{a}-\mathrm{b}}, \mathrm{H}_{2}$, and $\mathrm{H}_{4}$ were tested using a series of ANCOVAs, in which Hungarian objective vitality (LOV, HOV) was treated as the independent variable. Given that participants in the HOV group were slightly older and more likely to be female than those in the LOV group, as noted earlier, participants' age and sex were treated as covariates in all analyses. Subjective stress and health were included as additional covariates in the analysis of life satisfaction; although subjective health did not differ across the two groups, $t(375)=-.38, p=.71$, participants in the HOV group 
reported higher subjective stress $(M=2.72)$ than those in the LOV group $(M=2.56), t(375)=$ $2.03, p=.04$.

Subjective Hungarian vitality. Consistent with $\mathrm{H}_{1}$, the $\mathrm{HOV}$ group perceived local Hungarian vitality to be higher $(M=5.69)$ than the LOV group $(M=4.67), F(1,373)=77.59, p<.001, \eta_{\mathrm{p}}^{2}$ $=.17$. Neither age $(p=.73)$ nor sex $(p=.39)$ were significant covariates.

Subjective Romanian vitality. Consistent with $\mathrm{H}_{1 \mathrm{~b}}$, the $\mathrm{HOV}$ group perceived local Romanian vitality to be lower $(M=4.01)$ than the LOV group $(M=5.24), F(1,373)=85.67, p<.001, \eta_{\mathrm{p}}{ }^{2}$ $=.19$. Sex was a significant covariate, $F(1,373)=6.40, p=.01, \eta_{\mathrm{p}}{ }^{2}=.02$; female participants perceived Romanians to have more vitality than male participants. Age was a marginally significant covariate, $F(1,373)=3.77, p=.05, \eta_{\mathrm{p}}^{2}=.01$; older participants tended to rate Romanian vitality higher than younger participants.

Hungarian language use. Consistent with $\mathrm{H}_{2}$, the $\mathrm{HOV}$ group reported using more Hungarian $(M=.78)$ than the LOV group $(M=.57), F(1,373)=339.85, p<.001, \eta_{\mathrm{p}}^{2}=.48$. Neither age $(p$ $=.71)$ nor $\operatorname{sex}(p=.12)$ were significant covariates.

Life satisfaction. Consistent with $\mathrm{H}_{4}$, the $\mathrm{HOV}$ group reported higher life satisfaction $(M=3.52)$ than the LOV group $(M=3.30), F(1,374)=12.59, p<.001, \eta_{\mathrm{p}}^{2}=.03$. Several covariates were significant: female participants reported higher life satisfaction than male participants $[F(1,373)$ $\left.=18.41, p<.001, \eta_{\mathrm{p}}{ }^{2}=.05\right]$; subjective stress was negatively associated with life satisfaction $\left[F(1,373)=84.31, p<.001, \eta_{\mathrm{p}}^{2}=.19\right]$; and subjective health was positively associated with life satisfaction $\left[F(1,373)=58.85, p<.001, \eta_{\mathrm{p}}^{2}=.14\right]$. Age was not a significant covariate $(p=$ $.26)$.

[Insert Table 1 here] Mediation Analyses 
To test $\mathrm{H}_{4}, \mathrm{H}_{5} \mathrm{a}-\mathrm{b}$, and answer $\mathrm{RQ}_{1}$ and $\mathrm{RQ}_{2}$, the path model depicted in Figure 1 was specified in Mplus 7.2 (Muthén \& Muthén, 1998-2014). Zero-order correlations between all model variables are depicted in Table 1 . Objective vitality was dummy coded $(0=\mathrm{LOV}, 1=\mathrm{HOV})$. Subjective Hungarian and Romanian vitality were entered as parallel mediators, followed by Hungarian language use as the second mediator in the chain. Life satisfaction was treated as the dependent variable. Subjective Hungarian and subjective Romanian vitality were allowed to covary. All path model variables were treated as observed, except life satisfaction, which was treated as a single-indicator latent variable - with the indicator's (i.e., life satisfaction scale) factor loading fixed to 1 and its error variance fixed to $(1-\alpha)^{*}$ variance of the indicator - to correct for measurement error (see Kline, 2016). Consistent with the ANCOVAs described above, participants' age and sex were treated as covariates of all endogenous model variables; in addition, subjective health and subjective stress were entered as covariates of life satisfaction. The analysis used 10,000 bootstrap resamples. A given indirect was considered significant if its respective confidence interval did not contain 0 (Hayes, 2013). The obtained model with corresponding path coefficient is depicted in Figure 2. Overall model fit was good: $\chi^{2}(6)=19.86$, $p=.003, \mathrm{RMSEA}=.078(95 \% \mathrm{CI}: .04, .12), \mathrm{CFI}=.98, \mathrm{SRMR}=0.03$.

[Insert Figure 2 here]

The indirect effect of objective vitality on Hungarian language use via subjective Romanian vitality was significant $(B=.012,95 \% \mathrm{CI}=.002, .03)$; however, the indirect effect via subjective Hungarian vitality was not $(B=.007,95 \% \mathrm{CI}=-.003, .02)$. In other words, only subjective Romanian vitality mediated the effect of objective vitality on Hungarian language use; thus, $H_{3}$ was partially supported. With respect to $R Q_{1}$, the direct effect of objective vitality on Hungarian language use was reduced but remained significant, $B=.19,95 \% \mathrm{CI}=.16, .21-$ in 
other words, objective vitality continued to exert a significant direct effect on Hungarian language use even after controlling for subjective Hungarian and Romanian vitality.

The indirect effect of objective vitality on life satisfaction via subjective Hungarian vitality was significant $(B=.07,95 \% \mathrm{CI}=.02, .14)$; however, the indirect effects via subjective Romanian vitality $(B=-.03,95 \% \mathrm{CI}=-.10, .03)$, via Hungarian language use $(B=.05,95 \% \mathrm{CI}=$ $-.06, .16)$, sequentially via subjective Romanian vitality and language use $(B=.003,95 \% \mathrm{CI}=$ $.003, .02)$, and sequentially via subjective Hungarian vitality and language use $(B=.002,95 \% \mathrm{CI}$ $=-.002, .01)$ were all non-significant. In other words, only subjective Hungarian vitality mediated the effect of objective vitality on life satisfaction; thus, $\mathrm{H}_{5 \mathrm{a}}$ was partially supported, whereas $\mathrm{H}_{5 b}$ was not. With regard to $\mathrm{RQ}_{2}$, the direct effect of objective vitality on life satisfaction was rendered non-significant $(B=.12,95 \% \mathrm{CI}=-.06, .29)-$ in other words, once controlling for subjective Hungarian and Romanian vitality and Hungarian language use, objective vitality no longer exerted a significant direct effect on life satisfaction.

\section{Discussion}

The present study examined the relationship between objective and subjective vitality, relative language use, and life satisfaction among two groups of bilingual Hungarians living in Romania: a low objective vitality (LOV) group from Cluj-Napoca/Kolozsvár, where Hungarians are the demographic minority, and a high objective vitality (HOV) group from Sfântu Gheorghe/Sepsiszentgyörgy, where Hungarians are the demographic majority. Consistent with predictions, the HOV group reported higher subjective Hungarian vitality, lower subjective Romanian vitality, more frequent use of the Hungarian language, and higher life satisfaction, compared to the LOV group. The effects of objective Hungarian vitality on relative language use were partially mediated by subjective Romanian (but not Hungarian) vitality. Conversely, the 
effects of objective Hungarian vitality on life satisfaction were fully mediated by subjective Hungarian (but not Romanian) vitality. In other words, the HOV group used Hungarian relatively more frequently, in part, because they perceived Romanians to have less vitality in their respective locality; they reported higher life satisfaction, however, because they perceived Hungarians to have more vitality in their respective locality. These findings have a number of theoretical and practical implications.

First, to the best of our knowledge, this is the first study to empirically demonstrate that subjective vitality mediates the effect of objective vitality on relative language behavior. In so doing, it provides direct empirical support to the claim that language behavior is, at least partially, mediated by people's cognitive representations of the intergroup context (Johnson et al., 1983). Interestingly, however, it was only subjective outgroup vitality that mediated the relationship between objective vitality and language use, not subjective ingroup vitality. In other words, the HOV group used relatively more Hungarian than the LOV group not because the former perceived Hungarians to have more vitality, but because they perceived Romanians to have less vitality in their respective locality. Similar findings - wherein subjective outgroup, but not ingroup, vitality predicts language behavior - have been demonstrated in past research (e.g., Lawson \& Sachdev, 2004). Although it may be tempting to conclude that subjective outgroup vitality is a stronger predictor of language use than subjective ingroup vitality, we caution against this interpretation. In the present study, subjective ingroup (i.e., Hungarian) vitality was relatively high and above the scale midpoint for both groups $(p$ 's $<.001)$. It may be that this relatively high level of subjective Hungarian vitality was sufficient to instill a general tendency to speak Hungarian among both groups (i.e., ingroup language maintenance). If this is the case, then observed differences in relative language use across the two groups may reflect how 
perceived Romanian vitality constrains or inhibits this general tendency. Stated differently, some critical level of subjective ingroup vitality may be necessary to prompt ingroup language maintenance (i.e., a general tendency to use the ingroup language in everyday situations. Once that critical threshold is reached (and we believe it was in the present study), any additional increases in subjective ingroup vitality may have little effect on ingroup language use. Instead, factors that constrain or inhibit this language use predict variance from the "norm" of using the ingroup language. If this is indeed the case, it follows logically that increases in subjective ingroup vitality may have their strongest effect on ingroup language use when people perceive their ingroup to have relatively low vitality. However, when people already perceive their ingroup to have relatively high vitality, further increases in subjective ingroup vitality may have little bearing on language behavior. Future research should investigate this possibility.

Second, and notwithstanding the above, our findings also indicate that objective vitality can exert an effect on relative language behavior above and beyond the effects of subjective vitality. That is, even after controlling for subjective Hungarian and Romanian vitality, objective vitality still had an effect on language use, such that the HOV group used more Hungarian than the LOV group. Thus, although people's cognitive representations of the intergroup context clearly do have an effect on language use, as described above, so does objective reality. This should not be surprising: regardless of people's perceptions about their language's value or importance, these alone cannot drive language use; there need to exist objective opportunities to use the ingroup language. High objective vitality - especially when it is due to demographic and institutional support factors, as in the present study - may provide those opportunities by providing people with a larger network of linguistic ingroup contacts with whom to use the ingroup language (Landry \& Allard, 1992; Landry et al., 2010). Stated differently, people are 
likely to use the ingroup language more frequently when they have objective opportunities to do so, regardless of their perceptions. This finding reinforces the notion that both objective and subjective vitality are important predictors of language behavior (Harwood et al., 1994; Johnson et al., 1983).

Third, this study empirically demonstrates that intergroup differences in objective vitality can produce intergroup differences in life satisfaction, and that this effect is mediated by subjective vitality, even after controlling for subjective stress, health, and demographic factors (cf. Crozier, 1999; Currie \& Hogg, 1994). However, contrary to our findings pertaining to language use, the effects of objective vitality on life satisfaction were mediated only by subjective ingroup (but not outgroup) vitality. In other words, the reason the HOV group reported higher life satisfaction than the LOV group is because they perceived Hungarians to have more vitality in their respective locality, not because they perceived Romanians to have less vitality. This finding suggests that group members' psychological well-being may be more dependent on how they perceive and evaluate their ingroup than how they perceive other groups in the local context. That is, believing that one's ingroup is strong and active may enhance life satisfaction irrespective of beliefs about the strength and activity of relevant outgroups. As such, cultivating perceptions of ingroup vitality may be one way to promote ingroup morale and survival, even if such perceptions do not match objective reality. Interestingly, and contrary to predictions, ingroup language use had no bearing on life satisfaction. One possible reason for this null finding is that Hungarian language use was already relatively high among both groups; indeed, both the LOV and HOV groups reported speaking Hungarian more frequently than Romanian in their everyday lives (i.e., both groups were Hungarian-dominant). Had ingroup language use been relatively low, perhaps increased use of the ingroup language may have 
enhanced group members' life satisfaction. Another possibility is that perceived opportunities to use the ingroup language, which were likely higher among the HOV group, may have more bearing on life satisfaction that actual ingroup language use. As our data cannot speak directly to either of these explanations, future research should explore them further.

This study has several limitations that should be acknowledged. First, we used a singleitem measure of subjective vitality. Although our measure clearly had predictive validity - as demonstrated by its association to both language use and life satisfaction - and similar singleitem measures have been utilized in past research (e.g., Bourhis \& Sachdev, 1984; see also Noels, Kil, \& Fang, 2014), future studies should nonetheless attempt to replicate these findings using a multi-item measure that more fully captures the nuances of the vitality construct (for a discussion and critique of some existing measures, see Abrams et al., 2009; Allard \& Landry, 1994). Second, this study focused on only one ethnolinguistic group at a single point in time. Future studies should examine to what extent the effects described herein are generalizable to other ethnolinguistic groups, as well as how the nature of these relationships may change over time. Third, this study focused only on adolescents; given the potential for intergenerational differences in vitality perceptions (e.g., Yagmur \& Akinci, 2003), future research should extend these findings to other age groups. Finally, although our findings indicate that subjective ingroup vitality can influence life satisfaction, past research has shown that many other factors (which were not assessed in the present study) can also have bearing on this psychological construct (see Diener, 2009). Accordingly, future research should examine to what extent others factors potentially attenuate or accentuate the effects of subjective vitality on life satisfaction.

\section{Conclusion}


In sum, the present study demonstrates that intergroup variation in objective vitality predicts intergroup variation in language use and life satisfaction and that these effects are mediated by subjective vitality. These findings not only reinforce the utility of the vitality construct in explaining language behavior, but also its utility in explaining a broader range of intergroup phenomena, such as group members' psychological well-being. 


\section{Acknowledgements}

We would like to thank two anonymous reviewers and Howie Giles for their insightful feedback, which improved this article.

\section{Declaration of Conflicting Interests}

The author(s) declared no potential conflicts of interest with respect to the research, authorship, and/or publication of this article.

\section{Funding}

This research was supported by a grant from the Society of Swedish Literature in Finland. 


\section{References}

Abrams, J. R., Barker, V., \& Giles, H. (2009). An examination of the validity of the subjective vitality questionnaire. Journal of Multilingual and Multicultural Development, 30, 59-72.

Abrams, J. R., \& Giles, H. (2009). Hispanic television activity: Is it related to vitality perceptions? Communication Research Reports, 26, 247-252.

Allard, R., \& Landry, R. (1994). Subjective ethnolinguistic vitality: A comparison of two measures. International Journal of the Sociology of Language, 108, 117-144.

Berry, J. W. (1997). Immigration, acculturation, and adaptation. Applied Psychology: An International Review, 46, 5-68.

Berry, J. W. (2005). Acculturation: Living successfully in two cultures. International Journal of Intercultural Relations, 29, 697-712.

Berry, J. W., Phinney, J. S., Sam, D. L., \& Vedder, P. (2006). Immigrant youth: Acculturation, identity, and adaptation. Applied Psychology: An International Review, 55, 303-332.

Bourhis, R. Y. (1984). Cross-cultural communication in Montreal: two field studies since Bill 101. International Journal of the Sociology of Language, 46, 33-47.

Bourhis, R. Y., Giles, H., \& Rosenthal, D. (1981). Notes on the construction of a 'subjective vitality questionnaire' for ethnolinguistic groups. Journal of Multilingual and Multicultural Development, 2, 145-155.

Bourhis, R. Y., \& Sachdev, I. (1984). Vitality perceptions and language attitudes: Some Canadian data. Journal of Language and Social Psychology, 3, 97-126.

Branscombe, N. R., \& Wann, D. L. (1991). The positive social and self concept consequences of sports team identification. Journal of Sport and Social Issues, 15, 115-127. 
Chen, S. X., Benet-Martínez, V., \& Bond, M. H. (2008). Bicultural identity, bilingualism, and psychological adjustment in multicultural societies: Immigration-based and globalizationbased acculturation. Journal of Personality, 76, 803-838.

Cohen, S., Kamarck, T., \& Mermelstein, R. (1984). A global measure of perceived stress. Journal of Health and Social Behavior, 24, 385-396.

Cooper, K., Smith, L., \& Russell, A. (in press). Social identity, self-esteem, and mental health in Autism. European Journal of Social Psychology.

Crabtree, J. W., Haslam, S. A., Postmes, T., \& Haslam, C. (2010). Mental health support groups, stigma, and self-esteem: Positive and negative implications of group identification. Journal of Social Issues, 66, 553-569.

Crozier, S. (1999). An investigation into the correlations between ethnolinguistic vitality and well-being. Unpublished Masters Thesis: Concordia University, Montreal, Quebec, Canada.

Currie, M., \& Hogg, M. A. (1994). Subjective ethnolinguistic vitality and social adaptation among Vietnamese refugees in Australia. International Journal of the Sociology of Language, 108, 97-115.

Diener, E. (Ed.). (2009). Culture and well-being: The collected works of Ed Diener. New York, NY: Springer.

Diener, E., Emmons, R. A., Larsen, R. J., \& Griffin, S. (1985). The satisfaction with life scale. Journal of Personality Assessment, 49, 71-75.

Dragojevic, M. (2016). Language attitudes as intergroup terrain. In H. Giles \& A. Maass (Eds.), Advances in intergroup communication (pp. 51-66). New York, NY: Peter Lang. 
Gaudet, S., \& Clément, R. (2005). Identity maintenance and loss: Concurrent processes among Fransaskois. Canadian Journal of Behavioral Science, 37, 110-122.

Giles, H., Bourhis, R. Y., \& Taylor, D. M. (1977). Towards a theory of language in ethnic group relations. In H. Giles (Ed.), Language, ethnicity and intergroup relations (pp. 307-348). New York, NY: Academic Press.

Giles, H., \& Byrne, J. L. (1982). An intergroup approach to second language acquisition. Journal of Multilingual and Multicultural Development, 3, 17-40.

Giles, H., \& Johnson, P. (1981). The role of language in ethnic group relations. In J. C. Turner \& H. Giles (Eds.), Intergroup behavior (pp. 199-243). Oxford, UK: Basil Blackwell.

Giles, H., \& Johnson, P. (1987). Ethnolinguistic identity theory: a social psychological approach to language maintenance. International Journal of the Sociology of Language, 68, 69-99.

Harwood, J., Giles, H., \& Bourhis, R. Y. (1994). The genesis of vitality theory: historical patterns and discoursal dimensions. International Journal of the Sociology of Language, 108, 167-206.

Harwood, J., \& Vincze, L. (2012). Ethnolinguistic identity and television use in a minority language setting. Journal of Media Psychology, 24, 135-142.

Harwood, J., \& Vincze, L. (2015). Ethnolinguistic identity, vitality, and gratifications for television use in a bilingual media environment. Journal of Social Issues, 71(1), 73-89.

Haslam, S. A., Jetten, J., Postmes, T., \& Haslam, C. (2009). Social identity, health and wellbeing: An emerging agenda for social psychology. Applied Psychology: An International Review, 58, 1-23.

Hayes, A. F. (2013). Introduction to mediation, moderation, and conditional process analysis: A regression-based approach. New York, NY: Guilford Press. 
Heine, S. J. (2005). Where is the evidence for pancultural self-enhancement: A reply to Sedikides, Gaertner, and Toguchi (2003). Journal of Personality and Social Psychology, $89,531-538$.

Jetten, J., Branscobme, N. R., Haslam, A., Haslam, C., Cruwys, T., Jones, J. M., et al. (2015). Having a lot of a good thing: Multiple important group memberships as a source of selfesteem. PLOS ONE, 10, 1-29.

Johnson, P., Giles, H., \& Bourhis, R. Y. (1983). The viability of ethnolinguistic vitality: A reply. Journal of Multilingual and Multicultural Development, 4, 255-269.

Kline, R. B. (2016). Principles and practice of structural equation modeling (4 ${ }^{\text {th }}$ ed.). New York, NY: Guilford.

Kraemer, R., Olshtain, E., \& Badier, S. (1994). Ethnolinguistic vitality, attitudes, and networks of linguistic contact: the case of the Israeli Arab minority. International Journal of the Sociology of Language, 108, 79-95.

Landry, R., \& Allard, R. (1992). Ethnolinguistic vitality and the bilingual development of minority and majority group students. In W. Fase, K Jaespaert, \& S Kroon (Eds.), Maintenance and loss of minority languages (pp. 223-251). Amsterdam, Netherlands: Benjamins.

Landry, R., \& Allard, R. (1994). Diglossia, ethnolinguistic vitality, and language behavior. International Journal of the Sociology of Language, 108, 15-42.

Landry, R., Allard, R., \& Deveau, K. (2010). Schooling and cultural autonomy: A Canada-wide study in Francophone minority schools. Ottawa, Canada: Canadian Heritage.

Landry, R., \& Bourhis, R. Y. (1997). Linguistic landscape and ethnolinguistic vitality: An empirical study. Journal of Language and Social Psychology, 16, 23-49. 
Lawson, S., \& Sachdev, I. (2004). Identity, language use, and attitudes: Some SylhetiBangladeshi data from London, UK. Journal of Language and Social Psychology, 23, 4969.

Leary, M. R. (2007). Motivational and emotional aspects of the self. Annual Review of Psychology, 58, 317-344.

Marsiglia, F. F., Booth, J. M., Baldwin, A., \& Ayers, S. (2013). Acculturation and life satisfaction among immigrant Mexican adults. Advances in Social Work, 14, 49-64.

Marton, E., Joyce, N., \& Vincze, L. (2014). Ethnolinguistic vitality, attitudes and normative pressure as predictors of motivation in learning and speaking Hungarian as a second language in Slovenia. Journal of Estonian and Finno-Ugric Linguistics, 5, 57-70.

Muthén, B., \& Muthén, L. (1998-2014). Mplus user’s guide (7 $7^{\text {th }}$ ed.). Los Angeles, CA: Muthén \& Muthén.

Noels, K. A., \& Clément, R. (1996). Communicating across cultures: Social determinants and acculturative consequences. Canadian Journal of Behavioral Science, 28, 214-228.

Noels, K. A., Kil, H., \& Fang, Y. (2014). Ethnolinguistic orientation and language variation: Measuring and archiving ethnolinguistic vitality, attitudes, and identity. Language and Linguistics Compass, 8, 618-628.

Péntek, J., \& Benő, A. (2003). Nyelvi jogok Romániában [Language Rights in Romania]. In O. Nádor \& L. Szarka (Eds.), Kisebbségek, nyelvpolitika Kelet-Közép-Európában [Minorities and language policy in Central-Eastern Europe] (pp. 123-147). Budapest, Hungary: Akadémiai Kiadó.

Reid, S. A., Giles, H., \& Abrams, J. R. (2004). A social identity model of media usage and effects. Zeitschrift für Medienpsychologie, 16, 17-25. 
Rubin, M., \& Hewstone, M. (1998). Social identity theory's self-esteem hypothesis: A review and some suggestions for clarification. Personality and Social Psychology Review, 2, 4062.

Sachdev, I., Bourhis, R. Y., Phang, S-W., \& D’Eye, J. (1987). Language attitudes and vitality perceptions: Intergenerational effects among Chinese Canadian communities. Journal of Language and Social Psychology, 6, 287-307.

Sedikides, C., Gaertner, L., \& Vevea, J. L. (2005). Pancultural self-enhancement reloaded: A meta-analytic reply to Heine (2005). Journal of Personality and Social Psychology, 89, $539-551$.

Sedikides, C., Skowronski, J. J., \& Gaertner, L. (2004). Self-enhancement and self-protection motivation: From the laboratory to an evolutionary context. Journal of Cultural and Evolutionary Psychology, 2, 61-79.

Siedlecki, K. L., Salthouse, T. A., Oishi, S., \& Jeswani, S. (2014). The relationship between social support and subjective well-being across age. Social Indicators Research, 117, $561-576$.

Smith, B. K., Ehala, M., \& Giles, H. (in press). Vitality theory. In H. Giles \& J. Harwood (Eds.), Oxford research encyclopedia of intergroup communication. New York, NY: Oxford University Press.

Stell, G., \& Dragojevic, M. (2017). Multilingual accommodation in Namibia: An examination of six ethnolinguistic groups' language use in intra- and intergroup interactions. Journal of Language and Social Psychology, 36, 167-187.

Tabachnick, B. G., \& Fidell, L. S. (2007). Using multivariate statistics ( $5^{\text {th }}$ ed.). Boston, MS: Allyn \& Bacon. 
Tajfel, H., \& Turner, J. C. (1986). The social identity theory of intergroup behavior. In S. Worchel \& W. G. Austin (Eds.), Psychology of intergroup relations (pp. 7-24). Chicago, IL: Nelson-Hall.

Viladot, M. A., Giles, H., Gasiorek, J., \& Esteban-Guitart, M. (2012). Vitalidad etnolingüística, medios de comunicación e identidad étnica. Un estudio con grupos indígenas de Chiapas (México). [Ethnolinguistic vitality, mass media, and ethnic identity. A study with indigenous groups in the Chiapas (Mexico)]. Sociolinguistic Studies, 6, 471-490.

Vincze, L., \& Harwood, J. (2014). Objective local vitality and linguistic networks as predictors of perceived vitality. Journal of Multilingual and Multicultural Development, 35, 209215.

Yagmur, K., \& Akinci, M-A. (2003). Language use, choice, maintenance, and ethnolinguistic vitality of Turkish speakers in France: intergenerational differences. International Journal of the Sociology of Language, 164, 107-128.

Ytsma, J., Viladot, M. A., \& Giles, H. (1994). Ethnolinguistic vitality and ethnic identity: some Catalan and Frisian data. International Journal of the Sociology of Language, 108, 63-79. 
Table 1. Descriptives and Zero-Order Correlations between all Model Variables

\begin{tabular}{|c|c|c|c|c|c|c|c|c|c|c|c|}
\hline Variable & $M$ & $S D$ & 1 & 2 & 3 & 4 & 5 & 6 & 7 & 8 & 9 \\
\hline \multicolumn{12}{|l|}{ Main Variables } \\
\hline 1. City $(0=\mathrm{LOV} ; 1=\mathrm{HOV})$ & - & - & - & & & & & & & & \\
\hline 2. Subjective Hungarian vitality & 5.19 & 1.19 & $.42 * * *$ & - & & & & & & & \\
\hline 3. Subjective Romanian vitality & 4.62 & 1.39 & $-.41 * * *$ & $-.12 *$ & - & & & & & & \\
\hline 4. Hungarian language use & .67 & .15 & $.69 * * *$ & $.34 * * *$ & $-.63 * * *$ & - & & & & & \\
\hline 5. Life satisfaction & 3.41 & .71 & $.13 *$ & $.21 * * *$ & .05 & $.18 * * *$ & - & & & & \\
\hline \multicolumn{12}{|l|}{ Covariates } \\
\hline $6 . \operatorname{Sex}(0=$ male; $1=$ female $)$ & - & - & $.15^{* *}$ & .02 & .06 & .04 & .06 & - & & & \\
\hline 7. Age & 16.12 & .90 & $.20 * * *$ & .07 & .01 & $.12 *$ & -.06 & .04 & - & & \\
\hline 8. Subjective stress & 2.64 & .74 & $.10 *$ & -.04 & -.07 & -.03 & $-.46 * * *$ & $.24 * * *$ & .06 & - & \\
\hline 9. Subjective health & 3.76 & .84 & .02 & .08 & .08 & $.11 *$ & $.45 * * *$ & $-.14 * *$ & -.08 & $-.33 * * *$ & - \\
\hline
\end{tabular}

Note. LOV = low objective Hungarian vitality; HOV $=$ high objective Hungarian vitality; $n$ for all variables $=377 ; * p<.05, * * p<$ $.01, * * * p<.001$ 


\section{Author Biographies}

Marko Dragojevic (PhD, University of California, Santa Barbara) is an assistant professor in the Department of Communication at the University of Kentucky. His research focuses on language and interpersonal/intergroup communication.

Jessica Gasiorek (PhD, University of California, Santa Barbara) is an assistant professor in the Department of Communicology at the University of Hawai'i at Mānoa. Her research addresses message processing, intergroup dynamics, and issues related to communication and aging. Her published work includes both empirical articles and book chapters on communication accommodation theory, communication and successful aging, and communication in multilingual contexts.

László Vincze (PhD in communication, University of Helsinki, 2013) is a university lecturer at the Swedish School of Social Science, University of Helsinki. His most recent works have been published in International Journal of Applied Linguistics, Journal of Multilingual and Multicultural Development and Applied Linguistics Review. 